\title{
Karakteristik Refrigeran Musicool Dalam Mesin Refrigerasi Kompresi Uap Menggunakan Evaporator Ganda
}

 \\ 1Program Studi Mesin Otomotif, Universitas Muhammadiyah Magelang \\ ${ }_{2}^{2}$ Mahasiswa Program Studi Mesin Otomotif, Universitas Muhammadiyah Magelang \\ *Penulis korespondensi: bagiyo_condro@ummgl.ac.id
}

Histori artikel: diserahkan 20 Januari 2020, direviu 29 Januari 2020, direvisi 08 Februari 2020

\begin{abstract}
Musicool is an alternative refrigerant developed as a working fluid in a steam compression refrigeration system. Musicool has many advantages compared to conventional refrigerants, The advantage is that it is environmentally friendly. This study aims to determine the characteristics of musicool 134 on a steam compression refrigeration machine using a double evaporator. The test was done by comparing the characteristics of a single evaporator refrigeration machine and a double evaporator using musicool 134. The research variable is the airflow through the evaporator that is equal to $0.022 \mathrm{~kg} / \mathrm{s}, 0.027 \mathrm{~kg} / \mathrm{s}, 0.033 \mathrm{~kg} / \mathrm{s}$. The test data were taken measuring the temperature and pressureof each component in the refrigeration machine then using the P-h diagram musicool 134, to determine the refrigeration machines performance. The study results provide information that using a double evaporator will give rise to an improved refrigeration system performance compared to using a single evaporator.
\end{abstract}

Keywords: Vapor Compression Refrigeration system, musicool, hydrocarbons, multi evaporators.

DOI: $10.18196 /$ jqt.010208

Web: http://journal.umy.ac.id/index.php/qt

\section{PENDAHULUAN}

Penggunaan refrigeran dewasa ini sangat dipengaruhi oleh isu lingkungan yaitu Global Warming Potential (GWP) dan Ozone Depletion Potential (ODP) (Dalkilic \& Wongwises, 2010), (Purnomo \& Setiyo 2017), (Daly, 2006), (Han et al., 2013). Saat ini, penggunaan refrigeran kembali lagi seperti periode 1830 sampai 1930, yaitu menggunakan refrigeran alami atau natural seperti hydrocarbon ( $\mathrm{HC}), \mathrm{CO}_{2}, \mathrm{~N}_{2}$ dan lain-lain (Calm 2008). Refrigeran natural menjadi pilihan alternatif pengganti refrigeran CFCs maupun HFCs yang mempunyai efek tidak baik kepada lingkungan (Wang et al. 2010). Berikut ini beberapa Refrigeran komersial yang digunakan dalam beberapa dekade terakhir dan efeknya pada lingkungan disajikan pada tabel 1 .

Hidrokarbon (HC) menjadi refrigeran alternatif, yang telah lama diujicobakan, dan sekarang banyak digunakan dalam bebagai bidang air conditioning system. Propane (R-290) dan butane (R-600) serta campuran keduanya merupakan hidrokarbon yang memiliki sifat sangat baik sebagai refrigeran (Yang \& Wu 2013) (Teng et al., 2012). Penggunaan berbagai variasi campuran komposisi propane dan butane menunjukkan performa yang setara dengan R134a (Wongwises \& Chimres 2005) (Agrawal $\&$ Matani 2013).

Hidrokarbon memiliki keunggulan dan, kelemahan dibanding refrigeran sintetik. Kelemahan yang sangat menonjol adalah sifat mampu bakar (flammable) yang cukup tinggi dibandingkan refrigeran sintetik yang lain (Zhang et al., 2013) (Liao et al., 2005). Untuk mengurangi sifat mampu bakar tersebut dapat dilakukan dengan menambah gas inert seperti nitrogen $\left(\mathrm{N}_{2}\right)$ dan karbondioksida $\left(\mathrm{CO}_{2}\right)$ (Liao et al., 2005). Hal lain untuk mengurangi sifat mampu bakar tersebut yaitu dengan mendesain sistem dan peralatan yang akan mengurangi 
resiko terjadinya pembakaran akibat Conditioner) (Colbourne \& Suen, 2004). digunakannya $\mathrm{HC}$ dalam sistem AC (Air

TABEL 1. Properti beberapa refrigerants

\begin{tabular}{|c|c|c|c|c|c|c|}
\hline Refrigerants & $\begin{array}{l}\text { R134a } \\
\text { (HFC) }\end{array}$ & $\begin{array}{l}\text { R290 } \\
(\mathbf{H C})\end{array}$ & $\begin{array}{l}\text { R290 } \\
(\mathbf{H C})\end{array}$ & $\begin{array}{l}\mathrm{R} 290 / \mathrm{R} 600 \mathrm{a} \\
\text { mixture (HC) }\end{array}$ & $\begin{array}{l}\text { R152a } \\
\text { (HFC) }\end{array}$ & $\begin{array}{l}\text { R1234yf } \\
\text { (HFO) }\end{array}$ \\
\hline Global Warming Potential (GWP) & 1400 & 11 & 8 & 7 & 140 & 4 \\
\hline Ozone Depletion Potential (ODP) & 0 & 0 & 0 & 0 & 0 & 0 \\
\hline Atmospheric Life Time (years) & 14 & $<1$ & $<1$ & $<0.04$ & 2 & $<0.05$ \\
\hline $\begin{array}{l}\text { Acute Toxicity Exposure Level } \\
(\text { ATEL })(\text { ppm })\end{array}$ & 50,000 & 50,000 & 25,000 & 40,000 & 50,000 & 101,000 \\
\hline $\begin{array}{l}\text { Lower Flammability Limit (LFL) } \\
\text { (vol. \%) }\end{array}$ & - & 2.2 & 1.7 & 2.0 & 3.9 & 6.5 \\
\hline $\begin{array}{l}\text { Minimum Ignition Energy (MIE) } \\
\text { (mJ)/Safety Group }\end{array}$ & $-/ \mathrm{A} 1$ & $0.25 / \mathrm{A} 3$ & $0.25 / \mathrm{A} 3$ & N/A/A3 & $0.38 / \mathrm{A} 2$ & $>1000 / \mathrm{A} 2 \mathrm{~L}$ \\
\hline Molar Mass $(\mathrm{kg} / \mathrm{kmol})$ & 102.03 & 44.096 & 58.122 & N/A & 66.051 & N/A \\
\hline Vapor Density at $25^{\circ} \mathrm{C}(\mathrm{kg} / \mathrm{m} 3)$ & 32.35 & 20.65 & 9.12 & N/A & 18.47 & N/A \\
\hline Critical Temperature $\left({ }^{\circ} \mathrm{C}\right)$ & 101.1 & 96.8 & 135 & 114.8 & 113.3 & N/A \\
\hline Critical Pressure $(\mathrm{kPa})$ & 4061 & 4247 & 3647 & 4040 & 4522 & N/A \\
\hline Normal Boiling Point $(\mathrm{NBP})\left({ }^{\circ} \mathrm{C}\right)$ & -26.11 & -42.11 & -11.78 & -31.5 & -24.0 & N/A \\
\hline Vapor $\mathrm{Cp}$ at $25^{\circ} \mathrm{C}(\mathrm{kJ} / \mathrm{kg} \mathrm{K})$ & 1.0316 & 2.0724 & 1.8189 & 1.77 & 1.2536 & 1.0 \\
\hline
\end{tabular}

Refrigeran campuran antara propana dan butana dalam hal ini adalah LPG, juga dikembangkan sebagai sistem AC mobil hibrida menggunakan sistem setengah siklus, dimana LPG sebagai bahan bakar kendaraan dalam prosesnya terjadi perubahan fase dari cair ke gas sebelum masuk ke ruang bakar. Perubahan fase tersebut memelukan energi yang diambil dari udara sekitar (Setiyo et al., 2016). Bahkan telah diaplikasikan pada katup ekspansi dari material PTFE untuk meningkatkan performa dari sistem refrigerasi kompresi uap tersebut (Setiyo et al., 2017).

Sementara itu di Indonesia, refrigeran hydrocarbon (HC) yang sudah dikomersialkan adalah produk Pertamina dengan nama musicool. Musicool diproduksi oleh pertamina dalam beberapa varian yaitu musicool 12, musicool 22 dan musicool 134. Musicool merupakan refrigeran hidrokarbon yang memiliki kelebihan daripada refrigeran konvensional diantaranya adalah tidak perlu penggantian/penambahan komponen pada Mesin AC.

Peningkatan performa mesin AC menggunakan refrigeran musicool dilakukan dengan memvariasi jumlah aliran massa refrigeran yang masuk ke evaporator dengan mengatur luas penampang katup ekspansi (Bagiyo et al., 2015). Katup ekspansi ganda yang disusun secara parallel memberikan peningkatan performa refrigerasi, hal ini ditunjukkan dari peningkatan nilai COP (Purnomo et al., 2019). Sementara itu, masalah utama dalam system refrigerasi adalah ireversibelitas proses ekspansi isenthalpic, sehingga membuat penurunan performa sistem AC (Wongwises and Mongkut, 2016). Sementara itu penggunaan multi evaporator akan memberikan efisiensi yang lebih tinggi daripada single evaporator (Dwinanto et al., 2017). Penelitian ini bertujuan untuk mengetahui karakteristik sistem refrigerasi menggunakan evaporator ganda dengan refrigeran musicool.

\section{METODE PENELITIAN}

Penelitian ini dilakukan untuk mengetahu karakteristik refrigean musicool 134 dalam sistem refrigerasi kompresi uap dengan menggunakan evaporator ganda. Lingkup penelitian ini untuk mendapatkan karakteristik penggunaan evaporator tunggal dan ganda dalam system refrigerasi kompresi uap. Penelitian dilakukan menggunakan refrigeran musicool 134 dengan variasi beban pendinginan sebesar $0,22 \mathrm{Kg} / \mathrm{s}, 0,27 \mathrm{Kg} / \mathrm{s}$ dan $0,33 \mathrm{Kg} / \mathrm{s}$ yang diambil dari besarnya aliran massa udara yang melewati masing-masing evaporator.

Pengambilan data dilakukan dengan mengukur besarnya temperatur dan tekanan seperti yang 
ditunjukan pada Gambar 1. Hasil pengukuran berupa tekanan dan temperatur kemudian diplotkan pada $\mathrm{Ph}$ diagram musicool 134 untuk mendapatkan nilai dari entalphi masing-masing keadaan. Kemudian dihitung berapa nilai efek refrigerasi (ER), kerja kompresor (W-komp) dan coefficient of performance (COP)

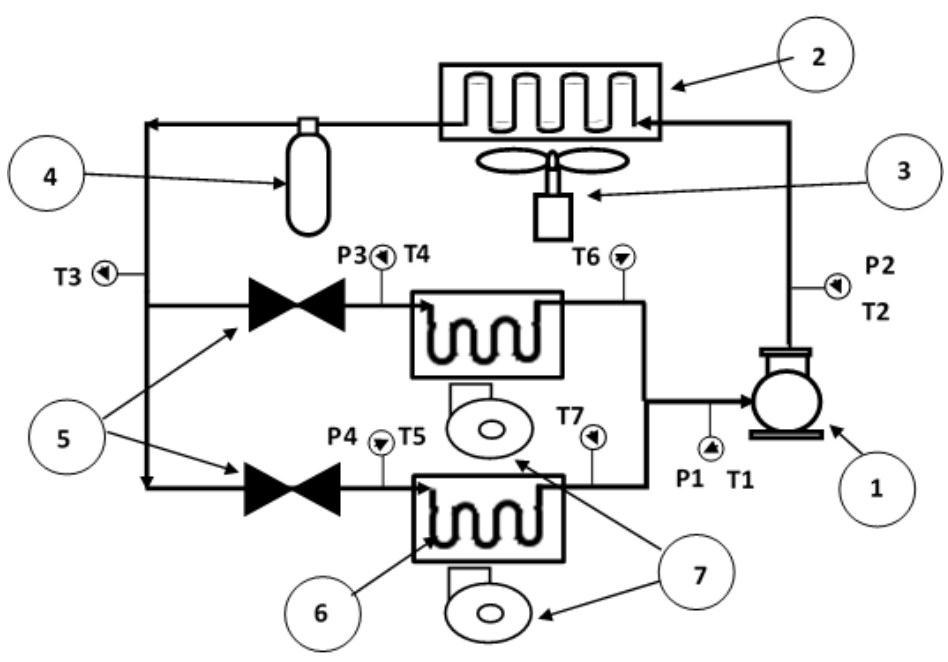

\begin{tabular}{ll}
\hline No & Keterangan \\
\hline 1 & Kompresor \\
\hline 2 & Kondensor \\
\hline 3 & Kipas \\
\hline 4 & Filter dryer \\
\hline 5 & Katup ekspansi \\
\hline 6 & Evaporator \\
\hline 7 & Blower \\
\hline
\end{tabular}

GAMBAR 1. Skema Penelitian

\section{HASIL DAN PEMBAHASAN}

Pada bagian ini menyajikan perbandingan karakteristik mesin refrigerasi kompresi uap menggunakan refrigeran musicool 134 dengan evaporator ganda dan tunggal. Data diambil untuk masing-masing posisi baik tekanan maupun temperatur seperti setup penelitian yang dijelaskan sebelumnya, data dicatat saat kondisi sudah stabil. Tabel 2 dan 3 berikut menunjukan hasil penelitian pada variasi beban pendinginan $0,22 \mathrm{~kg} / \mathrm{s}, 0,27 \mathrm{~kg} / \mathrm{s}$ dan $0,33 \mathrm{~kg} / \mathrm{s}$.

TABEL 2. Temperatur dan tekanan pada evaporator tunggal

\begin{tabular}{cccccccc}
\hline $\begin{array}{c}\text { Beban } \\
\begin{array}{c}\text { Pendinginan } \\
(\mathbf{K g} / \mathbf{s})\end{array}\end{array}$ & $\mathbf{T 1}\left({ }^{\circ} \mathbf{C}\right)$ & $\mathbf{T 2}\left({ }^{\circ} \mathbf{C}\right)$ & $\mathbf{T 3}\left({ }^{\circ} \mathbf{C}\right)$ & $\mathbf{T 4}\left({ }^{\circ} \mathbf{C}\right)$ & $\mathbf{T 5}\left({ }^{\circ} \mathbf{C}\right)$ & P1 (Psi) & P2 (Psi) \\
\hline 0,022 & 15 & 60 & 39 & 1 & 8 & 30 & 200 \\
\hline 0,027 & 14 & 60 & 38 & 0 & 7 & 30 & 200 \\
\hline 0,033 & 13 & 60 & 39 & 1 & 7 & 30 & 200 \\
\hline
\end{tabular}

TABEL 3. Temperatur dan tekanan pada evaporator ganda

\begin{tabular}{ccccccccccc}
\hline $\begin{array}{c}\text { Beban } \\
\begin{array}{c}\text { Pendinginan } \\
(\mathbf{K g} / \mathbf{s})\end{array}\end{array}$ & $\mathbf{T 1}\left({ }^{\circ} \mathbf{C}\right)$ & $\mathbf{T 2}\left({ }^{\circ} \mathbf{C}\right)$ & $\mathbf{T 3}\left({ }^{\circ} \mathbf{C}\right)$ & $\mathbf{T 4}\left({ }^{\circ} \mathbf{C}\right)$ & $\mathbf{T 5}\left({ }^{\circ} \mathbf{C}\right)$ & $\mathbf{T 6}\left({ }^{\circ} \mathbf{C}\right)$ & $\mathbf{T} 7\left({ }^{\circ} \mathbf{C}\right)$ & P1 (Psi) & P2 (Psi) \\
\hline 0,022 & 10 & 68 & 41 & 3 & 1 & 7 & 5 & 31 & 210 \\
\hline 0,027 & 9 & 71 & 43 & 1 & 0 & 8 & 4 & 31 & 210 \\
\hline 0,033 & 9 & 72 & 42 & 0 & -1 & 9 & 5 & 32 & 210 \\
\hline
\end{tabular}

Data pada tabel 2 dan 3 diplot di $\mathrm{Ph}$ diagram musicool 134 untuk menentukan besarnya entalphi masing-masing. Gambar 2 dan gambar
3 menunjukan hasil ploting pada diagram $\mathrm{Ph}$ Musicool 134 untuk evaporator tunggal dan 




GAMBAR 2. Ploting diagram Ph Musicool 134 untuk evaporator tunggal : A beban pendinginan $0,22 \mathrm{Kg} / \mathrm{s}$; $\mathrm{B}$ beban pendinginan $0,27 \mathrm{Kg} / \mathrm{s}$; C beban pendinginan $0,33 \mathrm{Kg} / \mathrm{s}$
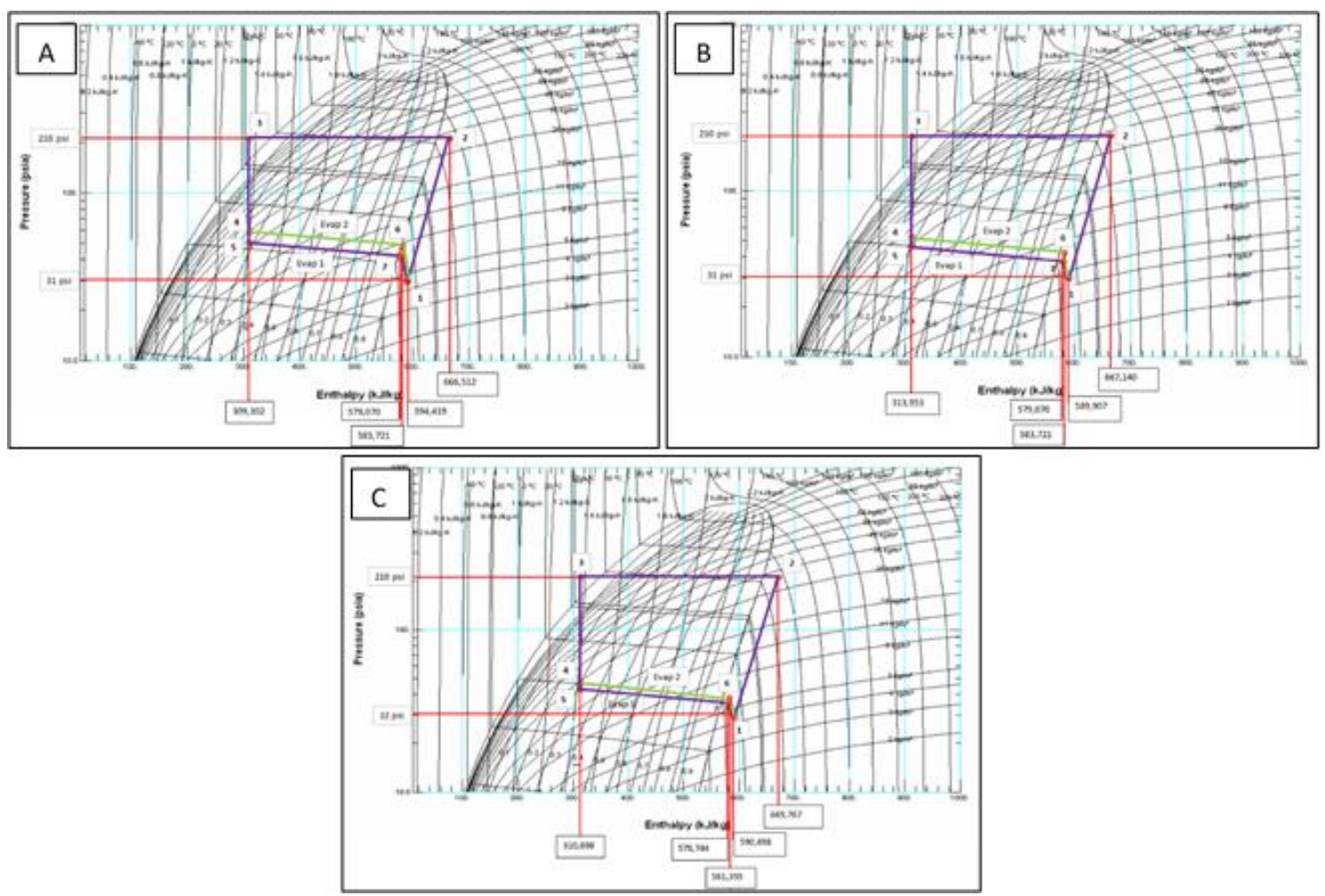

GAMBAR 3. Ploting diagram Ph Musicool 134 untuk evaporator ganda : A beban pendinginan $0,22 \mathrm{Kg} / \mathrm{s}$; $\mathrm{B}$ beban pendinginan $0,27 \mathrm{Kg} / \mathrm{s}$; C beban pendinginan $0,33 \mathrm{Kg} / \mathrm{s}$ 
Diagram P-h yang ditunjukkan pada Gambar 2 dan 3, sedangkan entalphi disajikan pada Tabel 4 dan 5. Enthalpi tersebut digunakan untuk mengetahui performa mesin refrigerasi kompresi uap dengan menggunakan refrigrant musicool 134 pada evaporator tunggal dan ganda pada setiap beban pendinginan. Koefisien kinerja (COP) dari mesin refrigerasi menggunakan evaporator ganda dapat dihitung menggunakan persamaan 1, (Dincer and Kanoglu 2010):

$C O P=\frac{\left(\dot{Q}_{\text {evap-1 }}+\dot{Q}_{\text {evap-2 }}\right)}{W_{\text {Comp }}}$

TABEL 4. Performa mesin refrigerasi dengan evaporator tunggal

\begin{tabular}{cccccccc}
\hline $\begin{array}{c}\text { Beban } \\
\begin{array}{c}\text { Pendinginan } \\
(\mathbf{K g} / \mathbf{s})\end{array}\end{array}$ & $\begin{array}{c}\mathbf{h} \mathbf{K J} / \mathbf{K g}) \\
(\mathbf{K J} / \mathbf{K g})\end{array}$ & $\begin{array}{c}\mathbf{h 3} \\
(\mathbf{K J} / \mathbf{K g})\end{array}$ & $\begin{array}{c}\mathbf{h 5} \\
(\mathbf{K J} / \mathbf{K g})\end{array}$ & $\begin{array}{c}\mathbf{E R} \\
(\mathbf{K J} / \mathbf{K g})\end{array}$ & $\begin{array}{c}\mathbf{W}-\mathbf{k o m p} \\
(\mathbf{K J} / \mathbf{K g})\end{array}$ & $\mathbf{C O P}$ \\
\hline 0,022 & 597,222 & 644,444 & 294,444 & 584,444 & 290 & 47,222 & 6,14121 \\
\hline 0,027 & 595,556 & 644,444 & 288,889 & 583,333 & 294,444 & 48,888 & 6,02283 \\
\hline 0,033 & 588,889 & 638,889 & 292,222 & 579,444 & 287,222 & 50,000 & 5,74444 \\
\hline
\end{tabular}

TABEL 5. Performa mesin refrigerasi dengan evaporator tunggal

\begin{tabular}{ccccccccccc}
\hline $\begin{array}{c}\text { Beban } \\
\begin{array}{c}\text { Pendinginan } \\
(\mathrm{Kg} / \mathrm{s})\end{array}\end{array}$ & $\begin{array}{c}\mathrm{h} 1 \\
(\mathrm{KJ} / \mathrm{Kg})\end{array}$ & $\begin{array}{c}\mathrm{h} 2 \\
(\mathrm{KJ} / \mathrm{Kg})\end{array}$ & $\begin{array}{c}\mathrm{h} 3 \\
(\mathrm{KJ} / \mathrm{Kg})\end{array}$ & $\begin{array}{c}\mathrm{h} 6 \\
(\mathrm{KJ} / \mathrm{Kg})\end{array}$ & $\begin{array}{c}\mathrm{h} 7 \\
(\mathrm{KJ} / \mathrm{Kg})\end{array}$ & $\begin{array}{c}\text { Qevap-1 } \\
(\mathrm{KJ} / \mathrm{Kg})\end{array}$ & $\begin{array}{c}\mathrm{Q} \text { evap-2 } \\
(\mathrm{KJ} / \mathrm{Kg})\end{array}$ & $\mathrm{ER}$ & $\begin{array}{c}\text { Wkomp } \\
(\mathrm{KJ} / \mathrm{Kg})\end{array}$ & $\mathrm{COP}$ \\
\hline 0,022 & 594,419 & 666,512 & 309,302 & 583,721 & 579,07 & 269,768 & 274,419 & 544,187 & 72,093 & 7,548 \\
\hline 0,027 & 589,767 & 667,14 & 313,953 & 583,721 & 579,07 & 265,117 & 269,768 & 534,885 & 77,373 & 6,913 \\
\hline 0,033 & 590,698 & 669,767 & 310,698 & 581,395 & 576,744 & 266,046 & 270,697 & 536,743 & 79,069 & 6,788 \\
\hline
\end{tabular}

Gambar 4 menunjukkan kinerja mesin refrigerasi kompresi uap dengan Musicool 134 dengan menggunakan evaporator tunggal dan ganda. Pada gambar tersebut dapat dilihat efek refrigerasi (ER) menyebabkan perubahan yang kecil terhadap perubahan beban pendinginan, akan tetapi terjadi penigkatan kerja kompresor terhadap perubahan beban pendinginan. Hal ini akan berimbas kepada perubahan sistem COP ang cenderung menurun pada evaporator tunggal maupun evaporator ganda.


GAMBAR 4. Performa mesin refrigerasi musicool 134 dengan evaporator tunggal (kiri) dan evaporator ganda (kanan)

Gambar 5 menunjukan perbandingan performa dari sistem refrigerasi kompresi uap dengan musicool 134 antara penggunaan evaporator tunggal dan ganda. Pada Gambar tersebut menjelaskan bahwa pengguanan evaporator ganda akan miningkatkan performa dari sistem. 
Efek refrigerasi mengalamai peningkatan yang sangat signifikan karena adanya efek refrigerasi pada masing-masing evaporator. Beban Kompresor pada evaporator ganda meningkatkan temperatur keluar pada kompresor. Penggunaan ini cukup besar apabila dibandingkan dengan penggunaan
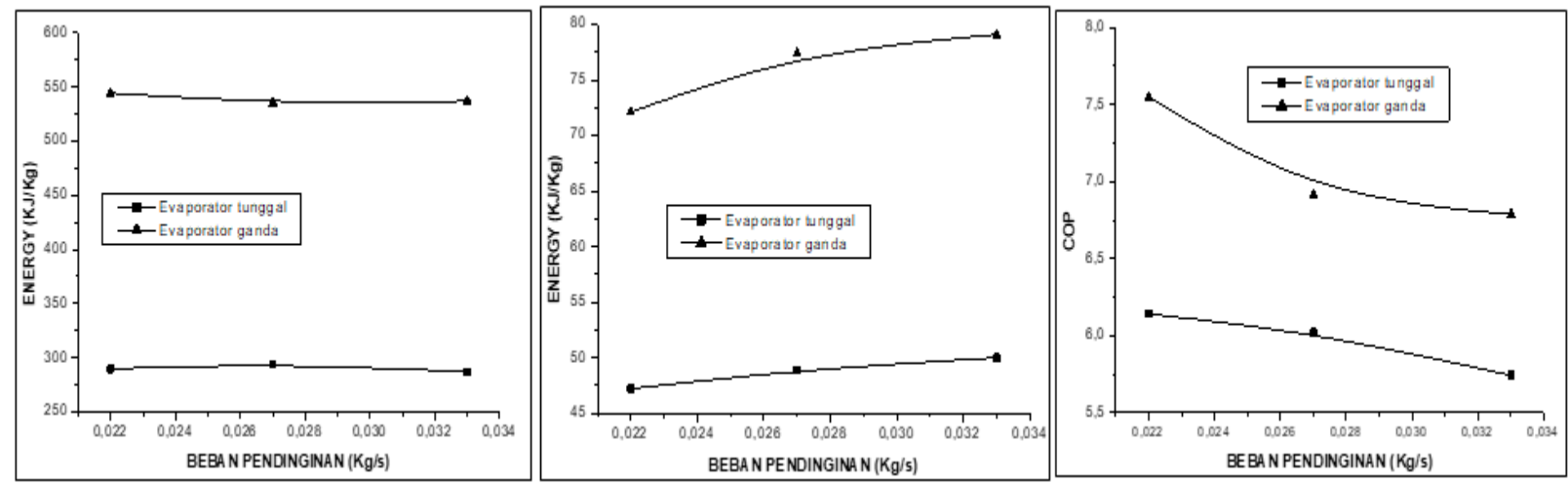

GAMBAR 5. Perbandingan performa sistem refrigerasi pada penggunaan evaporator tunggal dan evaporator ganda; efek refrigerasi (kiri); kerja kompresor (tengah; COP (kanan)

\section{KESIMPULAN}

Penggunaan evaporator ganda memberikan peningkatan performa sistem refrigerasi. Peningkatan signifikan terjadi pada efek refrigerasi dengan menggunakan evaporator ganda untuk setiap beban pendinginan. Sejalan dengan hal tersebut nilai COP juga mengalami peningkatan, akan tetapi performa kerja kompresor menurun dengan meningkatnya nilai kerja kompresor. Nilai COP terbaik terjadi pada penggunaan evaporator ganda pada beban pendinginan $22 \mathrm{Kg} / \mathrm{s}$ sebesar 7,55 sedang efek refrigerasi terbaik sebesar 544,12 $\mathrm{KJ} / \mathrm{Kg}$, kerja kompresor terendah terjadi pada penggunaan evaporator tunggal pada beban pendinginan $22 \mathrm{Kg} / \mathrm{s}$ sebesar 47,22 $\mathrm{KJ} / \mathrm{Kg}$. Penggunaan multi evaporator untuk dapat meningkatkan sistem refrigerasi, dapat diteliti lebih lanjut.

\section{UCAPAN TERIMA KASIH}

Penelitian ini terlaksana dengan baik karena banyak dukungan dan bantuan dari berbagai pihak. Untuk itu penulis mengucapkan banyak terima kasih kepada LP3M Universitas Muhammadiyah Magelang (UMM), Kepala Laboratorium Mesin Otomotif dan temanteman laboratorium Mesin Otomotif serta mahasiswa program studi Mesin Otomotif. evaporator tunggal. Kondisi tersebut maka dapat dipastikan COP juga akan miningkat.

\section{DAFTAR PUSTAKA}

Agrawal, Mukesh K, and Ashok G Matani, 2013. Evaluation of Vapour Compression Refrigeration System Using Different Refrigerants. International Journal of Engineering and Innovative Technology, 2(9), 8692.

Calm, J.M., 2008. The next generation of refrigerants-Historical review, considerations, and outlook. International Journal of Refrigeration, 31(7), pp.1123-1133.

Colbourne, D. and Suen, K.O., 2004. Appraising the flammability hazards of hydrocarbon refrigerants using quantitative risk assessment model Part I: modelling approach. International journal of refrigeration, 27(7), pp.774-783.

Dalkilic, A. S., and S. Wongwises. 2010. A Performance Comparison of VapourCompression Refrigeration System Using Various Alternative Refrigerants. International Communications in Heat and Mass Transfer 37(9): 1340-1349. Daly, Steven. 2006. Igarss 2014 Automotive Air Condiotining and Climate Control Systems. 
Dincer, Ibrahim, and Mehmet Kanoglu. 2010. Refrigeration Systems And Applications. Second Edi. A John Wiley and Sons, Ltd.

Dwinanto, Matheus, Suhanan Suhanan, and Prajitno Prajitno, 2017. Exergy Analysis of a Dual-Evaporator Refrigeration Systems Exergy Analysis of a Dual-Evaporator Refrigeration Systems. AIP Conference Proceedings.

Han, Xiao Hong et al., 2013. Cycle Performances of the Mixture HFC$161+$ HFC-134a as the Substitution of HFC-134a in Automotive Air Conditioning Systems. International Journal of Refrigeration 36(3): 91320.

Liao, S. Y., Q. Cheng, D. M. Jiang, and J. Gao, 2005. Experimental Study of Flammability Limits of Natural GasAir Mixture. Journal of Hazardous Materials 119(1-3): 81-84.

Purnomo, B.C., Setiyo, M., Waluyo, B. and Widodo, N., 2019. Characteristics of vapor compression refrigeration system with parallel expansion valves using refrigerant musicool 134. In IOP Conference Series: Materials Science and Engineering (Vol. 674, No. 1, p. 012006).

Purnomo, B.C. and Setiyo, M., 2017. Karakteristik sistem refrigerasi kompresi uap dengan refrigerant campuran musicool 134- $\mathrm{CO}_{2}$. Jurnal Teknologi, 9(2), pp.57-64.

Purnomo, B.C. and Budi W. 2015. Optimalisasi Penggunaan Refrigeran Musicool Untuk Meningkatkan Performa Sistem Refrigerasi Kompresi Uap Dengan Variabel Katup Ekspansi. Semnastek Universitas Muhammadiyah Jakarta (November): 1-7.

Setiyo, M., S. Soeparman, S. Wahyudi, and N. Hamidi. 2016. A Simulation for Predicting Potential Cooling Effect on LPG-Fuelled Vehicles. AIP Conference Proceedings 1717.

Setiyo, M., Saifudin, B.C.P., Waluyo, B. and Ramadhan, A.I., 2017. Temperature Distribution of R-134a Through Aluminum and PTFE Expansion Valve on Automotive Air Conditioning Applications. ARPN Journal of
Engineering and Applied Sciences, 12(4), pp.1046-1051.

Teng, T.P., Mo, H.E., Lin, H., Tseng, Y.H., Liu, R.H. and Long, Y.F., 2012. Retrofit assessment of window air conditioner. Applied Thermal Engineering, 32, pp.100-107.

Wang, Kai, Magnus Eisele, Yunho Hwang, and Reinhard Radermacher. 2010.

Review of Secondary Loop Refrigeration Systems. International Journal of Refrigeration 33(2): 21234.

Wongwises, S., Kamboon, A. and Orachon, B., 2006. Experimental investigation of hydrocarbon mixtures to replace HFC134a in an automotive air conditioning system. Energy Conversion and Management, 47(11-12), pp.1644-1659.

Wongwises, S. and Disawas, S., 2005. Performance of the two-phase ejector expansion refrigeration cycle. International journal of heat and mass transfer, 48(19-20), pp.4282-4286.

Yang, Z. and $\mathrm{Wu}, \mathrm{X} ., 2013$. Retrofits and options for the alternatives to HCFC-22. Energy, 59, pp.1-21.

Zhang, W., Yang, Z., Li, J., Ren, C.X., Lv, D., Wang, J., Zhang, X. and Wu, W., 2013. Research on the flammability hazards of an air conditioner using refrigerant R-290. International Journal of Refrigeration, 36(5), pp.1483-1494. 